\title{
Effects of an amylopectin and chromium complex on the anabolic response to a suboptimal dose of whey protein
}

\author{
T. N. Ziegenfuss ${ }^{1 *}$, H. L. Lopez ${ }^{1}$, A. Kedia', S. M. Habowski', J. E. Sandrock', B. Raub', C. M. Kerksick² \\ and A. A. Ferrando ${ }^{3}$
}

\begin{abstract}
Background: Previous research has demonstrated the permissive effect of insulin on muscle protein kinetics, and the enhanced insulin sensitizing effect of chromium. In the presence of adequate whole protein and/or essential amino acids (EAA), insulin has a stimulatory effect on muscle protein synthesis, whereas in conditions of lower blood EAA concentrations, insulin has an inhibitory effect on protein breakdown. In this study, we determined the effect of an amylopectin/chromium (ACr) complex on changes in plasma concentrations of EAA, insulin, glucose, and the fractional rate of muscle protein synthesis (FSR).
\end{abstract}

Methods: Using a double-blind, cross-over design, ten subjects (six men, four women) consumed $6 \mathrm{~g}$ whey protein $+2 \mathrm{~g}$ of the amylopectin-chromium complex (WPACr) or $6 \mathrm{~g}$ whey protein (WP) after an overnight fast. FSR was measured using a primed, continuous infusion of ring- $d_{5}$-phenylalanine with serial muscle biopsies performed at 2, 4, and $8 \mathrm{~h}$. Plasma EAA and insulin were assayed by ion-exchange chromatography and ELISA, respectively. After the biopsy at $4 \mathrm{~h}$, subjects ingested their respective supplement, completed eight sets of bilateral isotonic leg extensions at $80 \%$ of their estimated 1-RM, and a final biopsy was obtained $4 \mathrm{~h}$ later.

Results: Both trials increased EAA similarly, with peak levels noted 30 min after ingestion. Insulin tended $(p=0.09)$ to be higher in the WPACr trial. Paired samples t-tests using baseline and 4-h post-ingestion FSR data separately for each group revealed significant increases in the WPACr group $(+0.0197 \% / \mathrm{h}, p=0.0004)$ and no difference in the WP group $(+0.01215 \% / h r, p=0.23)$. Independent t-tests confirmed significant $(p=0.045)$ differences in post-treatment FSR between trials.

Conclusions: These data indicate that the addition of $\mathrm{ACr}$ to a $6 \mathrm{~g}$ dose of whey protein (WPACr) increases the FSR response beyond what is seen with a suboptimal dose of whey protein alone.

Keywords: Insulin, Chromium, Insulin sensitivity, Muscle protein synthesis, Amino acids

\section{Background}

The metabolism of muscle proteins operates in a continual flux whereby post-absorptive periods result in a dominance of muscle protein breakdown and net catabolism [1]. Alternatively, rates of muscle protein synthesis dominate after periods of feeding, particularly when those feedings include an adequate dose of the essential amino acids (EAA) [2-4]. In recent years, attempts to

\footnotetext{
*Correspondence: tz@appliedhealthsciences.org

${ }^{1}$ The Center for Applied Health Sciences, Division of Sports Nutrition and

Exercise Science, 4302 Allen Road, Suite 120, Stow, OH 44224, USA

Full list of author information is available at the end of the article
}

determine the optimal protein dose to maximize muscle protein synthesis have been undertaken. A number of studies have indicated a maximal anabolic response of muscle protein synthesis. Moore in 2009 first examined the differential ability of titrated doses of egg protein $(0$, $5,10,20$ and $40 \mathrm{~g}$ ) to stimulate muscle protein synthesis (MPS) rates and concluded that a 20-g dose resulted in a maximal response [5]. Yang and colleagues used identical whey protein doses as the Moore study in elderly men and found that after exercise a 40-g dose elicited a maximal response [6]. Wiitard and investigators examined progressive doses of whey protein (up $40 \mathrm{~g}$ ) 
and reported that a 20-g dose yielded the most robust response [7]. More recently, MacNaughton and colleagues reported that a $40-\mathrm{g}$ dose of whey protein was responsible for higher increases in MPS compared to a 20 -g dose, independent of how much lean mass an individual possessed. Collectively, these data suggest that a relative dose of approximately $0.18-0.40 \mathrm{~g}$ of protein per kilogram of body mass acutely elicits a maximal MPS response in humans $[8,9]$, depending on age and the presence of an exercise stimulus.

The role of insulin in muscle protein metabolism continues to garner interest from researchers. In the presence of adequate whole protein and/or EAA, insulin has a stimulatory effect on MPS, whereas in conditions of lower blood EAA concentrations, insulin has an inhibitory effect on protein breakdown with minimal impact of rates of muscle protein synthesis [10]. Consequently, any insulinogenic nutrient, or those that can improve insulin signaling, when combined with varying doses of EAA, could theoretically impact muscle protein balance. Indeed, Churchward-Venne and colleagues determined that a combination of added leucine (an essential amino acid with known insulinogenic properties [11]) and a dose of whey protein isolate that was deemed suboptimal $(6.25 \mathrm{~g})$ was able to favorably instigate acute increases in MPS and that the measured response of this combination was quantitatively similar to a $25 \mathrm{~g}$ dose of whey protein isolate [12]. Notably, the term "suboptimal" was used because of previous research that demonstrated submaximal muscle protein synthesis responses when absolutes doses of 5-10 $\mathrm{g}$ of protein were consumed [5].

In terms of insulin action, the trace mineral chromium continues to be investigated for its ability to improve insulin resistance and enhance insulin sensitivity in cell culture $[13,14]$, animal models [15] and humans [16, 17]. Collectively, these studies appear to indicate that chromium availability favorably impacts carbohydrate and lipid metabolism as well as GLUT-4 translocation. Furthermore, chromium appears to increase insulin responsiveness via an AMPK mediated pathway [18] and can instigate favorable changes to the insulin receptor [14]. Evans reported that supplementation with chromium picolinate improved cholesterol and glucose levels in non-diabetic and diabetic adults and was also associated with significant losses of fat mass and increases in lean mass [16]. Similarly, Kaats used a double-blind, placebo-controlled study to demonstrate that daily supplementation with chromium could favorably improve body composition in exercising humans [17]. While these studies point towards the ability of chromium to favorably impact various metabolic parameters, much more work needs to be done to clarify the impact that chromium may have on skeletal muscle physiology, particularly in populations that have suboptimal insulin sensitivity and/or protein kinetics.
Healthy aging (in the absence of other comorbidities) presents with increased levels of anabolic resistance that result in aged individuals needing to ingest higher amounts of protein to achieve maximal stimulation of MPS and the promotion of a positive balance of muscle protein $[6,19]$. In addition, studies have reported a lower intake of protein in the elderly [20] and a greater need for protein in the elderly [21]. When combined, these two factors result in a relative lack of optimal stimulation of MPS, which ultimately may be tied to the loss of skeletal muscle with aging [22-24]. Thus, nutritional strategies that may facilitate improvements in MPS with smaller doses of protein are of great interest to researchers and clinicians who work with these populations.

The purpose of this study was to examine potential differences in glucose, insulin, plasma amino acids, and muscle protein synthesis between a suboptimal dose of whey protein and a combination of chromium and amylopectin in combination with the same protein dose. It was hypothesized that ingestion of the chromiumcontaining product would improve insulin signaling and fractional synthesis rates of skeletal muscle proteins.

\section{Methods}

\section{Experimental approach}

This investigation was completed as a randomized, double-blind, single-dose, comparator-controlled crossover trial. Ten apparently healthy men $(n=6)$ and women $(n=4)$ between the ages of 22-34 years were pre-screened using health history questionnaires, vital signs, and blood work prior to being enrolled in the study. All subjects were required to report to the laboratory after observing an eight hour fast (including caffeine) with all testing sessions taking place at near identical times in the morning. Additionally, subjects were asked to avoid exercising for $72 \mathrm{~h}$ prior to each research visit. Research procedures included venous blood draws and vastus lateralis muscle biopsies during a primed, constant infusion of L-[ring- $\left.\mathrm{d}_{5}\right]$-phenylalanine (Cambridge Isotope Laboratories, Andover, MA). The fractional rate of muscle protein synthesis (FSR) was measured using the stable isotope tracer incorporation technique from vastus lateralis muscle biopsies performed two, four, and eight hours after initiating stable isotope tracer infusion. Blood samples were collected at baseline (time 0 ) and over an eight-hour time period $(240,270,300,330,360,390,420$ and $480 \mathrm{~min})$ to assess changes in amino acid concentrations. Similarly, glucose and insulin concentrations were analyzed in venous blood samples collected 240, 270, 300, 330, 360, 390 and $480 \mathrm{~min}$ after tracer infusion. A skeletal muscle biopsy was performed two and four hours after tracer initiation followed by a single dose of the assigned test product administered orally. Study participants then completed 
eight sets of bilateral isotonic leg extension resistance exercise at a load equivalent to approximately $80 \%$ of their estimated one-repetition maximum (1-RM). A third biopsy was obtained four hours after test product ingestion. A washout period of 5 to 7 days was utilized before each subject was crossed over to the opposite condition and scheduled to complete an identical testing session. The order in which test products were provided was counterbalanced to prevent any order effect.

\section{Study participants}

Ten healthy male $(n=6)$ and female $(n=4)$ participants (mean \pm SD: $26.6 \pm 3.7$ years, $175.5 \pm 10.9 \mathrm{~cm}, 78.56 \pm$ $17.4 \mathrm{~kg}$ ) were recruited to participate in this study. All participants read and signed an IRB-approved informed consent to participate document prior to their participation in the study (Integreview, Austin, TX; approval date: January 13, 2015). All participants completed a medical history and were screened by a study physician and determined to be normotensive and euglycemic with normal fasting insulin and HOMA-IR values. Potential participants were excluded if they had a history of diabetes, smoking, malignancy in the previous 6 months or any other clinical condition that the researchers felt would compromise their safe participation. Individuals who recently lost more than ten pounds, had prior bariatric procedures or were diagnosed or being treated for any chronic inflammatory condition or disease (Lupus, HIV/AIDS, etc.) were also excluded. Participants were not allowed to be taking any form of chromium supplements or any other dietary ingredient deemed by the research team to affect insulin sensitivity or glucose tolerance. Participants must have been regularly consuming animal proteins and agreed to continue following their normal resistance training and protein/amino acid supplementation patterns. Finally, participants were also excluded if they had a known allergy to wheat proteins, amylopectin or chromium, were regularly using any form of corticosteroids, anabolic-androgenic steroids or were already participating in another research study.

\section{Adverse event monitoring}

All study participants were required to record any adverse events throughout the entire study protocol. Participants were queried for symptoms during and after their completion of the study protocol to assess both the incidence and severity of adverse events according to CTCAE grading and MedDRA guidelines.

\section{Dietary and physical activity controls}

All study participants were asked to maintain their current dietary and exercise/physical activity habits. Care was taken to control diet and physical activity levels $24 \mathrm{~h}$ prior to each experimental trial as all participants were required to complete a $24-\mathrm{h}$ dietary recall prior to their initial experimental trial. A copy of this recall was made and all study participants were instructed to duplicate their dietary intake 24-h prior to their subsequent trial. As mentioned previously, all study participants were asked to refrain from exercise for $72 \mathrm{~h}$ prior to each visit and to fast for eight hours prior to testing. All dietary records were analyzed by the same research team member using the clinical edition of NutriBase IX (Phoenix, AZ).

\section{Subject preparation}

Participants reported to the laboratory after an overnight fast, were asked to void prior, and then height (in bare feet) and body mass were determined using a SECA Medical Scale (model 767, Hanover, Maryland USA). An 18-22-gauge polyethylene catheter was inserted into each arm by a research nurse; one was placed in a distal vein for heated blood sampling, and another was placed in the forearm for infusion of the stable isotope tracers.

\section{Blood sampling}

All blood samples were collected into lithium heparin tubes and centrifuged. Plasma samples were then aliquoted to minimize future freeze/thaw cycles and stored at $-80^{\circ} \mathrm{C}$ until analyses. Plasma blood samples $(5 \mathrm{ml})$ were collected at baseline $(0 \mathrm{~min})$ and after the beginning of isotope infusion $(240,270,300,330,360,390$, 420 and $480 \mathrm{~min}$ ) for analysis of amino acid concentrations and isotopic enrichment. Insulin and glucose concentrations in plasma were measured at 240, 270, 300, 330, 360, 390 and $480 \mathrm{~min}$ after baseline sampling.

\section{Amino acid (isotopic) tracer}

After insertion of peripheral catheters, a primed (5.04 $\mu \mathrm{mol} / \mathrm{kg})$, continuous $(0.084 \mu \mathrm{mol} / \mathrm{kg} / \mathrm{min})$ infusion of the stable isotope ring- $\mathrm{d}_{5}$-phenylalanine was initiated. Stable isotopes were obtained from Cambridge Isotope Laboratories (Andover, MA), compounded by a licensed pharmacy (Cantrell Pharmacy, Little Rock, AR) and tested for sterility and pyrogenicity prior to administration. Prior to infusion into the subject, the isotope solution was passed through a sterile $0.22 \mu \mathrm{m}$ (Millipore) filter.

\section{Muscle biopsy procedure}

Muscle biopsies from the vastus lateralis were performed two, four and eight hours after initiation of tracer infusion. After the biopsy at four hours, a single dose of WPACr or WP was administered orally under supervision. Muscle biopsies were performed under local anesthesia (using sterile 1\% lidocaine, without epinephrine) for pain management. A $5 \mathrm{~mm}$ Bergström needle was advanced into the muscle through a small $(\sim 1 \mathrm{~cm})$ 
incision. Immediately after applying suction, a sample of the muscle (approximately 100-120 mg) was removed with the needle. The sample was cleaned with sterile saline, trimmed of any visible connective tissue, blotted, and then cut into three equal portions $(\sim 30-40 \mathrm{mg})$. All three samples were immediately frozen in liquid nitrogen and stored at $-80^{\circ} \mathrm{C}$. One portion was utilized for determination of muscle protein synthesis, and the others were retained for backup analyses.

\section{Supplementation protocol}

Upon consent, study participants were randomly assigned in a double-blind fashion to one of two trials: 6 $\mathrm{g}$ of whey protein isolate (BiPro USA, Eden Prairie, $\mathrm{MN})+2 \mathrm{~g}$ of the test product (Velositol ${ }^{\mathrm{mm}}$ ) or $6 \mathrm{~g}$ of whey protein isolate. All provided supplements were prepared in powdered form and packaged in coded generic containers for double-blind administration and dissolved in $8 \mathrm{oz}$ of water immediately prior to oral dosing. All samples were blinded and matched for appearance, color, aroma and flavor by the study sponsor. Batch analysis of provided product at a third-party facility (Eurofins Scientific, Inc, Des Moines, IA USA, Certificate of Analysis \# AR-15-QD-031109-01) was completed of both WPACr and WP and results indicated that levels of all bioactive ingredients were consistent with those reported on the Supplement Facts Label (see Fig. 1). After a 5-7 day washout, subjects crossed over and completed the opposite trial. The order in which test products were provided was counterbalanced to prevent any order effect.

\section{Resistance exercise protocol}

As previously reported [25], all study participants then completed a single bout of bilateral leg extension exercise after supplement ingestion. Prior to beginning the study protocol all study participants determined their ten-repetition maximum and this load was used throughout the study. Each exercise trial consisted of eight sets of ten repetitions at their respective 10repetition maximum load. A traditional plate-loaded leg extension machine was used and $90 \mathrm{~s}$ of rest was provided between each set. All repetitions were performed

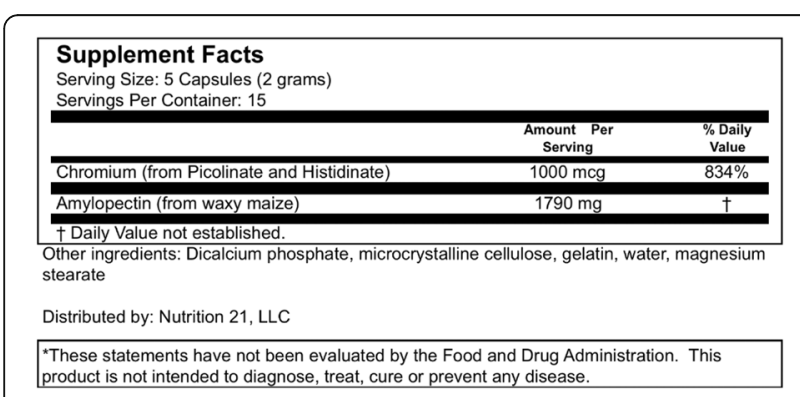

Fig. 1 Supplements facts label for $\mathrm{ACr}$ to near full-extension of the knee before returning to approximately $90-100^{\circ}$ of knee flexion. Participants were instructed to extend the knee through the concentric phase for two seconds, briefly pause and return the knee eccentrically for a two second period. Each repetition was supervised by research personnel to ensure the proper load was used, each repetition was completed, and an appropriate range of motion and lifting cadence was followed. If a participant became too fatigued during the initial session to complete any repetition, the weight was lowered and this adjustment was matched during the subsequent visit. Thus, since all participants were required to complete the same number of repetitions at the same weight load, volume was equal between trials (within subjects).

\section{Calculation of fractional synthesis rates of muscle protein synthesis}

Upon thawing, muscle tissues were weighed, and tissue proteins were precipitated with $0.5 \mathrm{ml}$ of $4 \%$ SSA. The tissues were then homogenized and then centrifuged for collection of supernatant. The procedure was repeated two more times, and tissue intracellular free AAs were extracted from the pooled supernatant via the same cation exchange chromatography stated in plasma analyses and then dried under the Speed Vac. The remaining muscle pellet was washed, dried, and hydrolyzed in $0.5 \mathrm{ml}$ of $6 \mathrm{~N} \mathrm{HCl}$ at $105{ }^{\circ} \mathrm{C}$ for $24 \mathrm{~h}$. Enrichments from muscle free and bound tracers were determined as in plasma analyses. Calculation of the fractional rate of muscle protein synthesis (FSR) was accomplished by the following equation:

$\operatorname{FSR}(\% / h r)=\left[\left(E_{p 2}-E_{p 1}\right) /\left(E_{m} \times t\right)\right] \times 60 \times 100$; where $E_{P 1}$ and $E_{P 2}$ are the enrichments of bound 1[ring $\left.{ }_{-}{ }^{2} \mathrm{H}_{5}\right]$ phenylalanine in the first and second biopsies, respectively, and $E_{m}$ is the calculated mean value of the enrichments of [ring-2H5] phenylalanine in the plasma pool. $t$ is the time in minutes elapsed between the first and second muscle biopsy. Factors 60 and 100 were used to express FSR in percent per hour (Kim et al. 2014).

\section{Statistical analyses}

A $p$-value of $\leq 0.05$ was used to indicate statistical significance and values from 0.051 to 0.10 were deemed a trend. In all cases data are presented as means \pm SD. All variables were tested for normality first using the Shapiro-Wilk test and followed up with individual skewness and kurtosis scores using 1.96 as a respective cut-off. Blood glucose, insulin and amino acid concentrations were compared using two-way factorial ANOVAs and t-tests when appropriate. Area under the curve (AUC) calculations were completed using the trapezoidal rule using Microsoft Excel (Seattle, WA). To investigate 
the presence of a gender effect due to our mixed gender cohort, a two-part approach was used. First, FSR data was analyzed using a univariate factorial ANOVA with gender and pre-treatment FSR as a covariate. Additionally, separate individual t-tests on both the pretreatment and post-treatment FSR data for both conditions and with them pooled together. In no situation was gender found to operate as a significant confounder; consequently, all FSR data was analyzed as a mixed gender cohort. Muscle FSR values were then compared using ANCOVA (using the pre-treatment FSR value as the covariate). In addition, post-treatment FSR values and within-trial changes in FSR were compared using dependent t-tests. Effect sizes and 95\% confidence intervals on the effect size were computed on the 4-h posttreatment FSR data. All statistical analysis and graphs were completed using IBM-SPSS for Windows, v21 (Armonk, NY) and Microsoft Excel (Seattle, WA).

\section{Results}

\section{Compliance and adverse events}

One female participant was initially removed after randomization due to dizziness that occurred after lidocaine injection and prior to the first muscle biopsy. This study participant was subsequently replaced by another eligible female. No mild, moderate or serious adverse events related to product ingestion were reported by any of the study participants.

\section{Dietary intake}

Study participants were $100 \%$ compliant in completing dietary records as well as replicating their food and fluid intake as instructed prior to each testing condition. Independent $\mathrm{t}$-tests revealed that energy (Male $[n=6]$ : $27.9 \pm 5.9 \mathrm{kcal} / \mathrm{kg} / \mathrm{day}$ vs. Female $[n=4]: 26.5 \pm 7.3 \mathrm{kcal} /$ $\mathrm{kg} /$ day, $p=0.74$ ), carbohydrate (Male: $2.6 \pm 0.8 \mathrm{~g} / \mathrm{kg} /$ day vs. Female: $3.0 \pm 0.6 \mathrm{~g} / \mathrm{kg} /$ day, $p=0.49$ ) and fat intake $(2.3 \pm 0.7 \mathrm{~g} / \mathrm{kg} /$ day vs. $1.7 \pm 0.3 \mathrm{~g} / \mathrm{kg} /$ day, $p=0.14)$ normalized to body mas in $\mathrm{kg}$ was not different between genders. Protein intake was greater $(p=0.003)$ in females $(1.7 \pm 0.2 \mathrm{~g} / \mathrm{kg} /$ day $)$ than in males $(1.2 \pm 0.2 \mathrm{~g} / \mathrm{kg} /$ day $)$.

\section{Plasma amino acid responses}

Total BCAA concentrations in both WPACr and WP peaked $30 \mathrm{~min}$ post-treatment (270 min time point) and remained elevated $(p<0.05)$ for another $30 \mathrm{~min}(300 \mathrm{~min}$ time point) before returning back to pre-treatment levels (Table 1). Two-way ANOVA revealed no trial $\mathrm{x}$ time interactions $(p=0.31)$ for changes in total branched-chain amino acids between the two conditions.

Individual serum concentrations of leucine, isoleucine and valine all followed a similar pattern of response with a significant increase $(p<0.05)$ occurring approximately $30 \mathrm{~min}$ after ingestion (270 min time point) and remained elevated for another $30 \mathrm{~min}$ (300 min time point). Two-way ANOVA revealed no trial $\mathrm{x}$ time interactions for leucine $(p=0.45)$, isoleucine $(p=0.51)$ and valine $(p=0.35)$ of these individual amino acids nor were pair-wise differences found to be statistically significant between trials at any time point. Amino acids responses are outlined in Table 1.

\section{Plasma glucose and insulin responses}

Two-way mixed factorial ANOVA revealed no significant trial $\mathrm{x}$ time interaction $(p=0.22)$ for plasma glucose responses. Significant within-trial reductions in plasma glucose were seen in WPACr in all time points after the 300 min time point. Independent $t$-tests comparing the AUC for plasma glucose responses in the first two hours (240-360 $\mathrm{min}, p=0.162)$ and four hours $(240-480 \mathrm{~min}$, $p=0.102$ ) after test product administration were not significant. Plasma glucose responses are outlined in Table 2.

Two-way mixed factorial ANOVA using plasma insulin responses revealed a trend $(p=0.09)$ for a trial $x$ time interaction. Within-trial changes in comparison to the 240 -min sample in both groups resulted in significant increases in plasma insulin concentrations $(p<0.05)$ at 270 and $300 \mathrm{~min}$ (30 and $60 \mathrm{~min}$ post-treatment, respectively). Independent $\mathrm{t}$-tests comparing the AUC for plasma insulin responses in the first two hours (240-360 min, $p=0.346)$ and four hours $(240-480 \mathrm{~min}, p=$ 0.478 ) after test product administration were not significant. Plasma insulin responses are outlined in Table 2.

Table 1 Plasma concentrations (means \pm SD) of leucine, isoleucine, valine and total BCAA for WPACr and WP across all time points

\begin{tabular}{|c|c|c|c|c|c|c|c|c|c|c|c|}
\hline & Group & $0 \mathrm{~min}$ & $120 \mathrm{~min}$ & $240 \mathrm{~min}$ & $270 \min$ & 300 min & $330 \mathrm{~min}$ & $360 \mathrm{~min}$ & $390 \mathrm{~min}$ & $420 \mathrm{~min}$ & $480 \min$ \\
\hline Leucine & WPACr & $122 \pm 24$ & $115 \pm 18$ & $113 \pm 16$ & $216 \pm 32^{\dagger}$ & $163 \pm 26^{\dagger}$ & $133 \pm 20$ & $128 \pm 19$ & $124 \pm 19$ & $124 \pm 17$ & $128 \pm 15$ \\
\hline$(\mu M)$ & WP & $105 \pm 25$ & $101 \pm 19$ & $103 \pm 24$ & $207 \pm 35^{\dagger}$ & $163 \pm 24^{\dagger}$ & $132 \pm 23^{\dagger}$ & $124 \pm 22^{\dagger}$ & $119 \pm 21^{\dagger}$ & $118 \pm 21^{\dagger}$ & $122 \pm 22^{\dagger}$ \\
\hline Isoleucine & WPACr & $65 \pm 15$ & $60 \pm 9^{\dagger}$ & $57 \pm 9^{\dagger}$ & $107 \pm 14^{\dagger}$ & $79 \pm 12^{\dagger}$ & $62 \pm 9$ & $59 \pm 9$ & $57 \pm 9^{\dagger}$ & $57 \pm 8$ & $60 \pm 7$ \\
\hline$(\mu \mathrm{M})$ & WP & $60 \pm 13$ & $56 \pm 9^{\dagger}$ & $57 \pm 12^{\dagger}$ & $110 \pm 19^{\dagger}$ & $84 \pm 14^{\dagger}$ & $67 \pm 12$ & $62 \pm 12$ & $60 \pm 10$ & $59 \pm 10$ & $62 \pm 11$ \\
\hline Valine & WPACr & $216 \pm 35$ & $207 \pm 30^{\dagger}$ & $197 \pm 27^{\dagger}$ & $254 \pm 38^{\dagger}$ & $222 \pm 29$ & $199 \pm 27^{\dagger}$ & $197 \pm 28^{\dagger}$ & $191 \pm 29^{\dagger}$ & $188 \pm 26^{\dagger}$ & $196 \pm 27^{\dagger}$ \\
\hline$(\mu \mathrm{M})$ & WP & $208 \pm 38$ & $198 \pm 32^{\dagger}$ & $199 \pm 33$ & $261 \pm 37^{\dagger}$ & $228 \pm 31$ & $205 \pm 34$ & $200 \pm 31$ & $196 \pm 31$ & $195 \pm 33^{\dagger}$ & $199 \pm 35$ \\
\hline Total BCAAs & WPACr & $404 \pm 71$ & $382 \pm 56^{\dagger}$ & $367 \pm 50^{+}$ & $576 \pm 81^{\dagger}$ & $464 \pm 64^{\dagger}$ & $394 \pm 53$ & $383 \pm 54$ & $372 \pm 55$ & $369 \pm 49$ & $384 \pm 48$ \\
\hline$(\mu \mathrm{M})$ & WP & $387 \pm 55$ & $364 \pm 45^{\dagger}$ & $371 \pm 58$ & $572 \pm 99^{\dagger}$ & $479 \pm 57^{\dagger}$ & $411 \pm 51$ & $394 \pm 50$ & $387 \pm 46$ & $380 \pm 50$ & $392 \pm 52$ \\
\hline
\end{tabular}

WPACr Whey protein + Amylopectin + Chromium, WP Whey protein, $\mu M$ micromoles. ${ }^{+}=$Significantly different from 0 min $(p<0.05)$ 
Table 2 Plasma concentrations (means \pm SD) of glucose and insulin for WPACr and WP across all time points

\begin{tabular}{llllllllll}
\hline & Group & $120 \mathrm{~min}$ & $240 \mathrm{~min}$ & $270 \mathrm{~min}$ & $300 \mathrm{~min}$ & $330 \mathrm{~min}$ & $360 \mathrm{~min}$ & $390 \mathrm{~min}$ & $480 \mathrm{~min}$ \\
\hline Glucose & WPACr & $5.37 \pm 0.34$ & $5.29 \pm 0.26$ & $5.27 \pm 0.33$ & $5.14 \pm 0.23$ & $5.14 \pm 0.19$ & $5.14 \pm 0.25$ & $5.04 \pm 0.27$ & $4.97 \pm 0.24$ \\
$(\mathrm{mM})$ & WP & $5.00 \pm 0.21$ & $5.07 \pm 0.45$ & $5.17 \pm 0.38$ & $5.06 \pm 0.27$ & $5.08 \pm 0.28$ & $5.02 \pm 0.31$ & $4.92 \pm 0.32$ & $4.88 \pm 0.28$ \\
Insulin & WPACr & $5.61 \pm 1.69$ & $4.50 \pm 1.48$ & $12.74 \pm 2.53^{\dagger}$ & $6.87 \pm 2.18^{\dagger}$ & $4.50 \pm 1.12$ & $3.81 \pm 1.15$ & $3.49 \pm 0.95^{\dagger}$ & $3.84 \pm 1.43$ \\
$(\mathrm{mlU} / \mathrm{mL})$ & WP & $4.68 \pm 2.28$ & $4.42 \pm 2.05$ & $10.0 \pm 4.32^{\dagger}$ & $6.13 \pm 2.62^{\dagger}$ & $4.69 \pm 1.83$ & $4.22 \pm 1.90$ & $3.77 \pm 1.43$ & $3.33 \pm 1.38$ \\
\hline
\end{tabular}

WPACr Whey protein + Amylopectin + Chromium, WP Whey protein, $\mu M$ micromoles, $\mathrm{ml} / \mathrm{mL}$ milliinternational units per milliliter of blood, ${ }^{\dagger}$ significantly different than 240 min time point $(p<0.05)$

\section{Muscle Fractional Synthesis Rate (FSR)}

Independent $\mathrm{t}$-tests were computed on both the pretreatment $(p=0.74)$ and $4-\mathrm{h}$ post-treatment $(p=0.76)$ FSR data for all conditions. In all instances, no significant differences were found between genders for either condition or when both condition were pooled at either time point.

Pre-treatment FSR data was not significantly different between WP and WPACr $(p=0.78)$. At the 4-h posttreatment time point, WPACr yielded a more robust FSR response (i.e. $48 \%$ increase from baseline) compared to the Control trial (24\% increase from baseline; Fig. 2). ANCOVA comparing the post-treatment FSR values (using the pre-treatment value as the co-variate) revealed a strong trend between trials $(p=0.054)$. Independent $\mathrm{t}$-tests confirmed significant $(p=0.045)$ differences in post-treatment FSR between trials, as well as a statistically significant (within-trial) increase using paired samples t-test during WPACr $(48 \%, p=0.0004)$ vs. a non-significant increase during the WP $(24 \%, p=$ $0.23)$. The average effect size for the 4 -h post-treatment data was 0.93 (95\% CI: 0.00-1.85), indicating a large treatment effect during the WPACr trial.

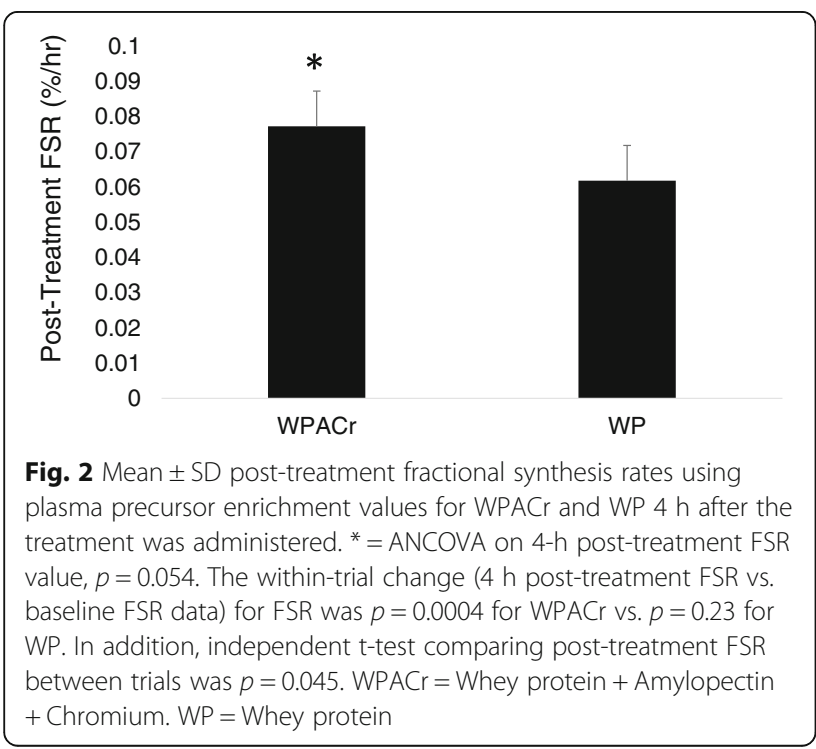

\section{Discussion}

The primary finding of the present study is that despite similar changes in plasma EAA responses, adding a novel amylopectin/chromium-containing complex to a suboptimal dose of whey protein magnified the increase in MPS from protein intake and resistance exercise (assessed four hours post-ingestion). A key strength of our study design is the randomized, counter-balanced, within-subject crossover approach we used to examine the potential differences between the two experimental conditions.

Of note, the MPS response with WPACr was approximately two times greater than the response seen in the whey protein only condition (i.e. $48 \%$ vs. $24 \%$ increase from baseline, Fig. 2). Mechanistically, amino acid levels significantly increased in both conditions, suggesting that the amount of substrate available for new muscle proteins to be resynthesized was not favorably tilted towards the WPACr trial. While it is tempting to speculate that the ACr complex afforded a more favorable biochemical environment upon which new proteins could be synthesized, this assertion is premature given our current study design. Future work examining the expression of various intramuscular signaling proteins (i.e., mTOR, p70s6k, etc.) is needed to explore this possibility.

To our knowledge, these results are among the first to illustrate the impact of a novel amylopectin chromiumcontaining complex on the stimulation of mixed muscle protein synthesis. In seeking an explanation for our study outcomes, the purported ability of chromium to favorably alter insulin metabolism $[14,26,27]$ is an important mechanistic consideration. This suggestion is supported by previous cell culture [13, 14], animal [15] and human work $[16,17]$ that has indicated chromium picolinate can improve carbohydrate and lipid metabolism, GLUT-4 translocation and others aspects of insulin metabolism. In this respect, Evans and Bowman reported that chromium picolinate can increase the internalization of insulin and markedly increase leucine uptake in cultured rat skeletal muscle cells [13]. Other cell culture work by Wang and colleagues reported that treatment of chromium in cultured human cells led to greater activation of insulin receptor kinase activity [14]. Cefalu used an animal model and concluded that oral chromium 
treatment significantly increased glucose and insulin areas under the curves as well as improved GLUT-4 metabolism leading them to conclude that chromium picolinate supplementation enhances insulin sensitivity and glucose disappearance [15]. Finally and in a series of human studies, Evans reported that 200 micrograms of chromium picolinate improved cholesterol and glucose levels in non-diabetic and diabetic adults, while two other studies in young men who were resistance training experienced significant losses of body fat and increases in lean mass [16]. Additional human work published in 1998 used a double-blind, placebo-controlled approach and also concluded that daily supplementation with chromium significantly improves multiple body composition parameters [17].

While the exact role(s) of insulin in muscle protein metabolism continues to be clarified, insulin has a demonstrated stimulatory effect on muscle protein synthesis when adequate EAA precursors are present, and seems to work more towards reducing muscle protein breakdown when EAA concentrations are reduced [10]. In this respect, investigating the post insulin receptor signal transduction pathways and phosphorylation cascades, including activation of IRS-1 (insulin receptor substrate-1) /PI3K (phosphatidylinositol-3 kinase)/Akt (protein kinase B)/mTORC /p70S6 kinase axis, are central to understanding the molecular mechanisms of muscle protein synthesis [28-30]. If WPACr acutely enhances these intracellular responses to insulin as indicated by previous work in culture [18], animal [13] and human studies [16], then it may potentially augment the anabolic response of skeletal muscle to an otherwise suboptimal dose of whey protein. This is an important consideration as the present study examined acute changes in fractional synthesis rates of mixed muscle proteins, but did not explore the impact of the chromium-containing compound on overall muscle protein balance, rates of muscle protein breakdown, or whole-body net protein balance. It is also worth mentioning that an interaction between the whey protein and amylopectin could have also impacted the observed changes in muscle FSR, however, this interaction is deemed minimal. The inclusion of amylopectin was primarily from a formulary perspective to operate as a transport vehicle; further, the provided dosage $(\sim 2 \mathrm{~g})$ has not been shown to exhibit a substantive physiological impact.

While our four-hour post-treatment FSR changes provide encouraging preliminary evidence that the chromiumcontaining complex may potentiate the anabolic response seen in a mixed muscle sample after a resistance training stimulus, these conclusions have potential limitations (e.g., small sample size and our mixed gender cohort). In this respect, our sample size is quite consistent with previous studies that have employed similar study designs using identical methodologies that are known to have excellent sensitivity for detecting changes in FSR [2-4]. In addition, any impact of gender was deemed minimal because our independent ttests between genders on all FSR data revealed no instance where gender differences were present, as did univariate factorial ANOVA with gender as a covariate. These findings support previous work by Markofski that demonstrated no difference in basal rates of MPS between genders [31]. In addition, it is acknowledged that our muscle biopsy samples were analyzed as a mixed muscle sample and thus the observed effects may or may not be specific to myofibrillar protein synthesis.

The fitness and athletic communities could potentially benefit from our findings through identification of means to drive muscle anabolism while reducing the overall daily caloric load. Additionally, the aging and insulin resistant populations are particularly intriguing candidates for translation of this line of research into practice. In particular, the aged have previously been shown to exhibit a certain level of anabolic resistance to the stimulatory effect of amino acids [19] resulting in larger doses of the essential amino acids and intact proteins required to stimulate maximal rates of muscle protein synthesis [6]. This is problematic given evidence suggesting that protein intake in the elderly is reduced [20].

\section{Conclusions}

In conclusion, this study demonstrates that the addition of the amylopectin/chromium-containing complex to a suboptimal dose of whey protein [12] improves the muscle anabolism response to acute resistance exercise beyond that of the protein dose alone in young, healthy subjects. Future research should confirm these data and seek to better understand the mechanisms responsible for the observed results.

\section{Acknowledgements \\ The amylopectin/chromium complex was provided by Nutrition 21, LLC under the trademark Velositol ${ }^{\mathrm{Tm}}$. The authors would like to thank all of the study participants who completed the study protocol. Publication of these results should not be considered an endorsement of any product used in this study by the Center for Applied Health Sciences or any of the organizations where the authors are affiliated. \\ Funding \\ Funding for this study was provided by Nutrition 21, LLC (Purchase, NY) through a restricted grant. The sponsor of the study was not involved in the conduct, interpretation or preparation of the final manuscript. A third-party (independent) laboratory audited the collected data for accuracy and performed the statistical analyses.}

\section{Availability of data and materials}

The data and materials for this manuscript are not scheduled to be made publicly available due to the proprietary nature of the investigated materials. Contractually, the data is owned by Nutrition 21, LLC, not any of the authors.

\section{Authors' contributions}

TZ, HL and AF designed the study, secured funding for project, assisted with data analysis and manuscript preparation. AK provided medical oversight, subject screening, subject recruitment and assisted with data collection and 
manuscript preparation. SH, JS, and BR carried out subject recruitment, data collection, coordination of the study and compliance. CK assisted with data analysis and helped prepare the manuscript. All authors read and approved the final manuscript.

\section{Competing interests}

Dr. Ziegenfuss has no conflict in terms of financial or business interests related to this product. Dr. Ziegenfuss has received grants and contracts to conduct research on dietary supplements; has served as a paid consultant for industry; has received honoraria for speaking at conferences and writing lay articles about protein and other sports nutrition ingredients (but not the product investigated in this study): receives royalties from the sale of several sports nutrition products (but not from Nutrition 21, LLC); and has served as an expert witness on behalf of the plaintiff and defense in cases involving dietary supplements. Dr. Ziegenfuss is also co-inventor on multiple patent applications within the field of dietary supplements, applied nutrition and bioactive compounds.

Dr. Lopez has no conflict in terms of financial or business interests related to this product. Dr. Lopez is an officer and member of The Center for Applied Health Sciences, a privately held contract research organization that has received external funding from companies that does business in the dietary supplement, natural products, medical foods and functional foods and beverages industry. He is cofounder and member of Supplement Safety Solutions, LLC., serving as an independent consultant for regulatory compliance, safety surveillance and Nutravigilance to companies in the dietary supplement and functional foods industry, but not Nutrition 21, LLC., the sponsor of the current research. Dr. Lopez is also co-inventor on multiple patent applications within the field of dietary supplements, applied nutrition and bioactive compounds.

Dr. Kerksick has no conflict in terms of financial or business interests related to this product. Dr. Kerksick has received external grant funding from companies that do business in the nutrition and sports nutrition sectors and he has been paid to speak and prepare scientific manuscripts including white papers and marketing copy on topics related to sports nutrition. He has and continues to serve in advisory roles to various sport nutrition and nutrition companies. Dr. Ferrando has no conflict in terms of financial or business interests related to this product. Dr. Ferrando was involved in the initial experimental design based upon his experience and expertise. Plasma and muscle samples were sent to his laboratory for analyses. Analytical costs were paid by the sponsor. All samples were coded and blinded to treatment. After assurance of data quality and grouping, treatment identification was released from the sponsor for interpretation and manuscript preparation.

Dr. Kedia, Mr. Habowski, Ms. Sandrock and Ms. Raub all report no conflicts of interest.

\section{Consent for publication}

This section is not applicable as our manuscript does not contain any individual or identifying data.

\section{Ethics approval and consent to participate}

All participants read and signed an IRB-approved informed consent to participate document prior to their participation in the study (Integreview, Austin, TX; approval date: January 13, 2015). NOTE: This statement is also found in the 'Study Participants' section of the manuscript.

\section{Author details}

${ }^{1}$ The Center for Applied Health Sciences, Division of Sports Nutrition and Exercise Science, 4302 Allen Road, Suite 120, Stow, OH 44224, USA. ²Exercise and Performance Nutrition Laboratory, School of Health Sciences, Lindenwood University, 209 S. Kingshighway St., Charles, MO 63301, USA. ${ }^{3}$ The University of Arkansas for Medical Sciences, 4301 West Markham, Little Rock, AR 72205, USA.

Received: 25 July 2016 Accepted: 1 February 2017

Published online: 08 February 2017

\section{References}

1. Tipton KD, Wolfe RR. Exercise, protein metabolism, and muscle growth. Int J Sport Nutr Exerc Metab. 2001;11:109-32.

2. Phillips SM, Tipton $K D$, Aarsland $A$, et al. Mixed muscle protein synthesis and breakdown after resistance exercise in humans. Am J Physiol. 1997;273:E99-107.
3. Biolo G, Tipton KD, Klein S, et al. An abundant supply of amino acids enhances the metabolic effect of exercise on muscle protein. Am J Physiol. 1997;273:E122-9.

4. Borsheim E, Tipton KD, Wolf SE, et al. Essential amino acids and muscle protein recovery from resistance exercise. Am J Physiol Endocrinol Metab. 2002;283:E648-57.

5. Moore DR, Robinson MJ, Fry JL, et al. Ingested protein dose response of muscle and albumin protein synthesis after resistance exercise in young men. Am J Clin Nutr. 2009;89:161-8.

6. Yang $Y$, Breen L, Burd NA, et al. Resistance exercise enhances myofibrillar protein synthesis with graded intakes of whey protein in older men. $\mathrm{Br} J$ Nutr. 2012;108:1780-8.

7. Witard OC, Jackman SR, Breen L, et al. Myofibrillar muscle protein synthesis rates subsequent to a meal in response to increasing doses of whey protein at rest and after resistance exercise. Am J Clin Nutr. 2014;99:86-95.

8. Phillips SM. A brief review of higher dietary protein diets in weight loss: A focus on athletes. Sports Med. 2014;44 Suppl 2:S149-53.

9. Morton RW, McGlory C, Phillips SM. Nutritional interventions to augment resistance training-induced skeletal muscle hypertrophy. Front Physiol. 2015;6:245.

10. Wolfe RR. Effects of insulin on muscle tissue. Curr Opin Clin Nutr Metab Care. 2000;3:67-71.

11. Dreyer HC, Drummond MJ, Pennings B, et al. Leucine-enriched essential amino acid and carbohydrate ingestion following resistance exercise enhances mtor signaling and protein synthesis in human muscle. Am J Physiol Endocrinol Metab. 2008;294:E392-400.

12. Churchward-Venne TA, Burd NA, Mitchell CJ, et al. Supplementation of a suboptimal protein dose with leucine or essential amino acids: Effects on myofibrillar protein synthesis at rest and following resistance exercise in men. J Physiol. 2012;590:2751-65.

13. Evans GW, Bowman TD. Chromium picolinate increases membrane fluidity and rate of insulin internalization. J Inorg Biochem. 1992;46:243-50.

14. Wang $\mathrm{H}$, Kruszewski A, Brautigan DL. Cellular chromium enhances activation of insulin receptor kinase. Biochemistry. 2005;44:8167-75.

15. Cefalu WT, Wang ZQ, Zhang XH, et al. Oral chromium picolinate improves carbohydrate and lipid metabolism and enhances skeletal muscle glut-4 translocation in obese, hyperinsulinemic (jcr-la corpulent) rats. J Nutr. 2002; 132:1107-14.

16. Evans GW. The effect of chromium picolinate on insulin controlled parameters in humans. Int J Biosocial Med Research. 1989;11:163-80.

17. Kaats GR, Blum K, Pullin D, et al. A randomized, double-blind, placebocontrolled study of the effects of chromium picolinate supplementation on body composition: A replication and extension study of a previous study. Curr Ther Res. 1998;59:379-88.

18. Hoffman NJ, Penque BA, Habegger KM, et al. Chromium enhances insulin responsiveness via ampk. J Nutr Biochem. 2014;25:565-72.

19. Cuthbertson D, Smith K, Babraj J, et al. Anabolic signaling deficits underlie amino acid resistance of wasting, aging muscle. FASEB J. 2005;19:422-4.

20. Rousset S, Patureau Mirand P, Brandolini M, et al. Daily protein intakes and eating patterns in young and elderly french. Br J Nutr. 2003;90: 1107-15.

21. Campbell WW, Trappe TA, Wolfe RR, et al. The recommended dietary allowance for protein may not be adequate for older people to maintain skeletal muscle. J Gerontol A Biol Sci Med Sci. 2001;56:M373-80.

22. Petrella JK, Kim JS, Mayhew DL, et al. Potent myofiber hypertrophy during resistance training in humans is associated with satellite cell-mediated myonuclear addition: a cluster analysis. J Appl Physiol. 2008;104:1736-42.

23. Kosek DJ, Kim JS, Petrella JK, et al. Efficacy of 3 days/wk resistance training on myofiber hypertrophy and myogenic mechanisms in young vs. older adults. J Appl Physiol. 2006;101:531-44.

24. Lexell J, Taylor CC, Sjostrom M. What is the cause of the ageing atrophy? Total number, size and proportion of different fiber types studied in whole vastus lateralis muscle from 15- to 83-year-old men. J Neurol Sci. 1988;84:275-94.

25. Tipton KD, Elliott TA, Ferrando AA, et al. Stimulation of muscle anabolism by resistance exercise and ingestion of leucine plus protein. Appl Physiol Nutr Metab. 2009;34:151-61.

26. Vincent JB. The biochemistry of chromium. J Nutr. 2000;130:715-8.

27. Vincent JB. Recent advances in the nutritional biochemistry of trivalent chromium. Proc Nutr Soc. 2004;63:41-7.

28. Greiwe JS, Kwon G, McDaniel ML, et al. Leucine and insulin activate p70 s6 kinase through different pathways in human skeletal muscle. Am J Physiol Endocrinol Metab. 2001;281:E466-71. 
29. Sykiotis GP, Papavassiliou AG. Serine phosphorylation of insulin receptor substrate-1: A novel target for the reversal of insulin resistance. Mol Endocrinol. 2001;15:1864-9.

30. Baar $\mathrm{K}$, Blough $\mathrm{E}$, Dineen $\mathrm{B}$, et al. Transcriptional regulation in response to exercise. Exerc Sport Sci Rev. 1999;27:333-79.

31. Markofski MM, Dickinson JM, Drummond MJ, et al. Effect of age on basal muscle protein synthesis and mtorc1 signaling in a large cohort of young and older men and women. Exp Gerontol. 2015;65:1-7.

Submit your next manuscript to BioMed Central and we will help you at every step:

- We accept pre-submission inquiries

- Our selector tool helps you to find the most relevant journal

- We provide round the clock customer support

- Convenient online submission

- Thorough peer review

- Inclusion in PubMed and all major indexing services

- Maximum visibility for your research

Submit your manuscript at www.biomedcentral.com/submit 